\title{
The pollution levels of BTEX and carbonyls under haze and non-haze days in Beijing, China
}

\author{
Yujie Zhang a,b , Yujing Mu ${ }^{\text {b,* }}$, Fan Meng a , Hong Li ${ }^{\text {a }}$, Xuezhong Wang a , Weiqi Zhang a , Abdelwahid Mellouki ${ }^{\text {, }}$ \\ Jian Gao ${ }^{a}$, Xinmin Zhang ${ }^{a}$, Shulan Wang ${ }^{a}$, Fahe Chai ${ }^{a}$ \\ a State Key Laboratory of Environmental Criteria and Risk Assessment, Chinese Research Academy of Environmental Sciences, Beijing 100012, China \\ ${ }^{\mathrm{b}}$ Research Center for Eco-Environmental Sciences, Chinese Academy of Sciences, Beijing 100085, China \\ c Centre National de Recherche Scientifique-Institut de Combustion, Aérothermique, Réactivité et Environnement (CNRS-ICARE), 45071 Orléans cedex 02, France
}

\section{H I G H L I G H T S}

- Remarkable accumulation of carbonyls and BTEX was found under haze days.

- Photochemical reactivity exhibited to be stronger under haze days.

- Local emissions depressed by haze resulted to the higher ratios in winter.

\section{A R T I C L E I N F O}

Article history:

Received 24 October 2013

Received in revised form 27 April 2014

Accepted 6 May 2014

Available online 24 May 2014

Editor: Xuexi Tie

\section{Keywords:}

Carbonyls

BTEX

Haze

Photochemical reaction

Local emission

\begin{abstract}
A B S T R A C T
The North China Plain including Beijing is frequently suffering from serious haze days in recent years. To best recognize the influence of haze days on regional air quality, the pollution levels of deleterious gases of BTEX (benzene, toluene, ethylbenzene, m,p-xylene and o-xylene) and carbonyls (formaldehyde, acetaldehyde and acetone) under haze and non-haze days were contrastively investigated during the period of September 2008August 2010 in Beijing. In comparison with non-haze days, remarkable enhancement of BTEX and the carbonyls under haze days in winter was found, with enhancement factors of 1.9-5.7 for BTEX and of 1.5-4.2 for the carbonyls. Whereas the enhancement factors for both BTEX (1.0-3.0) and the carbonyls (1.2-1.9) under haze days in summer were relatively small. The ratios of each BTEX to CO under both haze days and non-haze days exhibited a minimal value in the afternoon, whereas maximal values for the ratios of the carbonyls to CO were usually found in the afternoon. The ratios of each BTEX to CO were extremely greater under haze days than those under non-haze days in winter, but no evident difference was found in summer. The ratios of each carbonyl under both haze days and non-haze days in summer were at least a factor of 2 greater than those in winter and only enhancement of the ratios under haze days was found in winter. The remarkably higher ratios of ethylbenzene to $\mathrm{m}$,p-xylene under haze days than non-haze days in both winter and summer revealed high reactivity of photochemical reactions initiated by $\mathrm{OH}$ radicals under haze days.
\end{abstract}

C 2014 Elsevier B.V. All rights reserved.

\section{Introduction}

Carbonyl and BTEX (benzene, toluene, ethylbenzene, $m, p$-xylene and $o$-xylene) compounds are receiving increasing attention as the key participants in photochemical reactions and their adverse effect on human health (Haagen-Smit and Fox, 1956; Committee on Toxicology and Environmental Health Hazards, 1981; Carlier et al., 1986; Atkinson, 1997; Hoque et al., 2008). They are both recognized as important photochemical precursors for tropospheric ozone and second organic aerosols

\footnotetext{
* Corresponding author. Tel.: + 861062849125 .

E-mail addresses: Zhangyujie83@126.com (Y. Zhang), yjmu@rcees.ac.cn (Y. Mu).
}

(Wang et al., 2002; Barletta et al., 2008). Besides, photolysis of the carbonyls is an important source for atmospheric hydroxyl radical $(\mathrm{OH})$ and peroxy radicals $\left(\mathrm{HO}_{2}, \mathrm{RO}_{2}\right)$, which are further involved in photochemical reactions (Carlier et al., 1986; Atkinson and Arey, 2003). BTEX and a number of carbonyl compounds are well-known toxic air pollutants (TAPs). Benzene, formaldehyde and acetaldehyde are even considered as human carcinogens (Stupfel, 1976; Crump, 1994; Carlier et al., 1986; Baez et al., 2003; Dutta et al., 2009).

It is well known that the concentrations of atmospheric pollutants near the earth surface are strongly affected by their sources' strength (local or transported), atmospheric chemical processes (production/ removal) and meteorological conditions (wind, precipitation, the 
Planetary Boundary Layer (PBL), etc.). Remarkable accumulation of atmospheric pollutants usually occurs under stagnant air condition (slow wind speed and low PBL), which has caused serious atmospheric environmental problems, e.g. haze is frequently raiding on vast areas of China in recent years. Most Chinese studies are focusing on measurements of particle matter to reveal the deterioration of air quality under haze days, but few studies are concerning the influence of haze on the deleterious gases of BTEX and carbonyls. Lü et al. (2009) found that the average total concentration of carbonyls in Guangzhou under hazy days in winter was a factor of 1.0-4.0 higher than those under clear days. Liu et al. (2009a) studied the influence of haze on levels of atmospheric BTEX and ratios of ethylbenzene/benzene (E/X) in summer of 2008 in Beijing and reported that both the concentrations and the ratio increased under haze days. Mao et al. (2008) investigated the vertical distributions of volatile organic compounds (including aromatic hydrocarbons) in the atmosphere of Beijing under haze and clear days, and they reported that the average concentrations of total volatile organic compounds under hazy days were greater by $7.6 \%$ to $89 \%$ than those under clear days. All above studies well revealed that remarkable enhancement of the deleterious gases under haze days. However, the above studies mainly focused on the influence of haze on atmospheric levels of carbonyls or BTEX during only one season by investigating a very short period (1-3 clear days in comparison with 1-3 haze days).

In this study, the atmospheric BTEX and carbonyls in Beijing were analyzed in-depth with the data measured during the period of September 2008-August 2010 to reveal the influence of haze on their levels and ratios during different seasons.

\section{Materials and methods}

\subsection{Sampling site}

Air samples were collected on a rooftop (20 m above the ground level) in the Research Center for Eco-Environmental Sciences (RCEES) which lies in the north of Beijing city $\left(39.8^{\circ} \mathrm{N}, 116.5^{\circ} \mathrm{E}\right)$ between the 4 th and 5th rings roads. The detail information about the sampling site was described in our previous studies (Pang and Mu, 2006; Liu et al., 2009a).

\subsection{Sampling and analysis}

Carbonyls and BTEX were simultaneously sampled at least 4 days per month from September 2008 to August 2010, with carbonyls' samples collected at $2 \mathrm{hr}$ interval and BTEX at $1 \mathrm{hr}$ interval. Nearly all kinds of weather were tried to be covered each month to collected samples, excepting raining day: at least one clear day, one cloudy day, one haze day with average wind speed lower than $3 \mathrm{~m} \mathrm{~s}^{-1}$, and one wind day with hourly average wind speed higher than $5 \mathrm{~m} \mathrm{~s}^{-1}$.

The sampling process and analysis procedure of atmospheric carbonyls were mainly based on the EPA TO-11A method (EPA, 1999), and the details have been described in our previous publications (Pang and Mu, 2006, 2007). Briefly, ambient air was drawn through a 2,4-dinitrophenylhydrazine (DNPH)-coated silica gel cartridge (Waters, United States) by a mini-pump (NMP 830 KNDC, Germany) at a flow rate of $800 \mathrm{Ml} \mathrm{min}^{-1}$ for $2 \mathrm{~h}$, and the corresponding DNPH hydrazones of carbonyls were separated by a Thermo ODS Hypersil reverse phase column $(5 \mu \mathrm{m}, 250 \mathrm{~mm} \times 4.6 \mathrm{~mm})$ and automatically analyzed by an photodiode array UV detector (at $360 \mathrm{~nm}$ ) in an Alliance 2695 HPLC system (Waters, USA). The detected limit $(S / N=3)$ by this method was in the range of $80-200 \mathrm{ng} \mathrm{m}^{-3}$ for various carbonyls of $96 \mathrm{~L}$ sampling volume.

As for BTEX, they were sampled by drawing air through an absorption tube (15 cm long, $4 \mathrm{~mm}$ ID) filled with Tenax-TA (80-100 mesh, $100 \mathrm{mg}$ ) at a flow rate of $350 \mathrm{~m} \mathrm{~min}^{-1}$ for $1 \mathrm{hr}$, and analyzed by a gas chromatography equipped with a Photo Ionization Detector (GC-PID, GC4400, East \& West Analytical Instruments, Inc.) after thermal desorption. The method detection limit (with a signal-to-noise ratio of 2 ) for the benzene, toluene, ethylbenzene, $m, p$-xylene and $o$-xylene was $0.01,0.02,0.06,0.07$ and $0.07 \mu \mathrm{g} \mathrm{m}^{-3}$, respectively. One blank sample was analyzed for each day, and found that the concentrations of BTEX in the blank tube were less than 3\% of those in the ambient air samples. Distinct breakthrough for benzene was found when the absorption tube was kept under ambient air temperature, but greatly improved when the tube was kept in a bath of ice-salt bag. Therefore, all samples were collected under the bath of ice-salt bag, and the collection efficiencies for benzene, toluene, ethylbenzene, $m, p$-xylene and $o$-xylene were $(81.5 \pm 5.6) \%$, (93.6 \pm 2.2$) \%$, $(95.8 \pm 0.8) \%,(96.5 \pm 2.4) \%$ and $(91.5 \pm 4.6) \%$ (the result of 10 reduplicate experiments with two absorption tubes in series), respectively. The recovery ratios for benzene, toluene, ethylbenzene, $m, p$ xylene and $o$-xylene were $(95.7 \pm 3.1) \%,(99.2 \pm 2.6) \%,(98.6 \pm 2.4) \%$, $(98.1 \pm 2.4) \%$ and $(96.2 \pm 2.2) \%$ (the result of 22 reduplicate experiments), respectively. The details about preparation of the absorption tube, sampling and analyzing procedures have been described in our previous publication (Liu et al., 2009a).

Meteorological conditions (temperature, wind speed, atmospheric pressure and precipitation) during the investigated years were recorded by an automatic meteorological station (the Beijing Urban Ecosystem Research Station, RCEES) located at the same site. Ozone concentrations in summers and winter of 2008 to 2010 were provided by the Chinese Research Academy of Environmental Science (CRAES) which lies in the north of Beijing city $\left(40^{\circ} 2^{\prime} \mathrm{N}, 116^{\circ} 24^{\prime} \mathrm{E}\right)$ between 5th and 6 th ring roads.

\section{Results and discussion}

\subsection{The influence of haze days on the atmospheric BTEX}

The identification of haze days was based on the visibility $(<5 \mathrm{~km})$ and relative humidity $(<80 \%)$. Because haze days usually occur under stagnant air condition, to eliminate the influence of strong wind and precipitation for comparison, only the days with wind speed less than $3 \mathrm{~m} \mathrm{~s}^{-1}$ and without precipitation were selected for comparison of the pollutants between haze days and non-haze days. Among the 30 sampling days during the two winter seasons, there were 7 typical haze days, 2 snowy days, 6 windy days and 15 remaining days classified as non-haze days. During the two summer seasons, there were 15 haze days, 2 windy days and 16 non-haze days.

Fig. 1 illustrates the average diurnal variations of BTEX under haze days and non-haze days in winter and summer. It is evident that the hourly average concentrations of each BTEX compound under haze days were much higher than those under non-haze days both in winter and summer. The hourly average concentrations of benzene, toluene, ethylbenzene, $m, p$-xylene and $o$-xylene were about factors of 1.9-4.0, 2.3-5.7, 2.4-4.6, 2.2-4.0, and 2.2-3.6 respectively greater under haze days than those under non-haze days in winter, whereas were factors of 1.2-3.0, 1.1-2.5, 1.1-2.4, 1.0-2.4, and 1.0-2.4 respectively greater under haze days than those under non-haze days in summer. The enhancement of BTEX under haze days was mainly ascribed to the evolution of the PBL which was strongly depressed and weakened the diffusion of pollutants (Quan et al., 2013). In comparison with winter, the remarkable small enhancement of BTEX under haze days in summer indicated less BTEX sources, greater BTEX consumption through photochemical reactions and higher height of PBL in summer than in winter.

The ratios of the hourly averaged concentrations of each BTEX compound to $\mathrm{CO}$ under haze days and non-haze days in winter and summer is listed in Table 1. As the BTEX compounds and CO are mainly from the same primary sources in the urban area and $\mathrm{CO}$ is a relative chemical inert pollutant, the ratios of BTEX to $\mathrm{CO}$ would be useful indicators for photochemical reactivity, because the ratios could partly counteract the influence of diffusion (Satsumabayashi et al., 1995; Possanzini et al., 2002). As it could be seen from Table 1, the ratios of each BTEX 

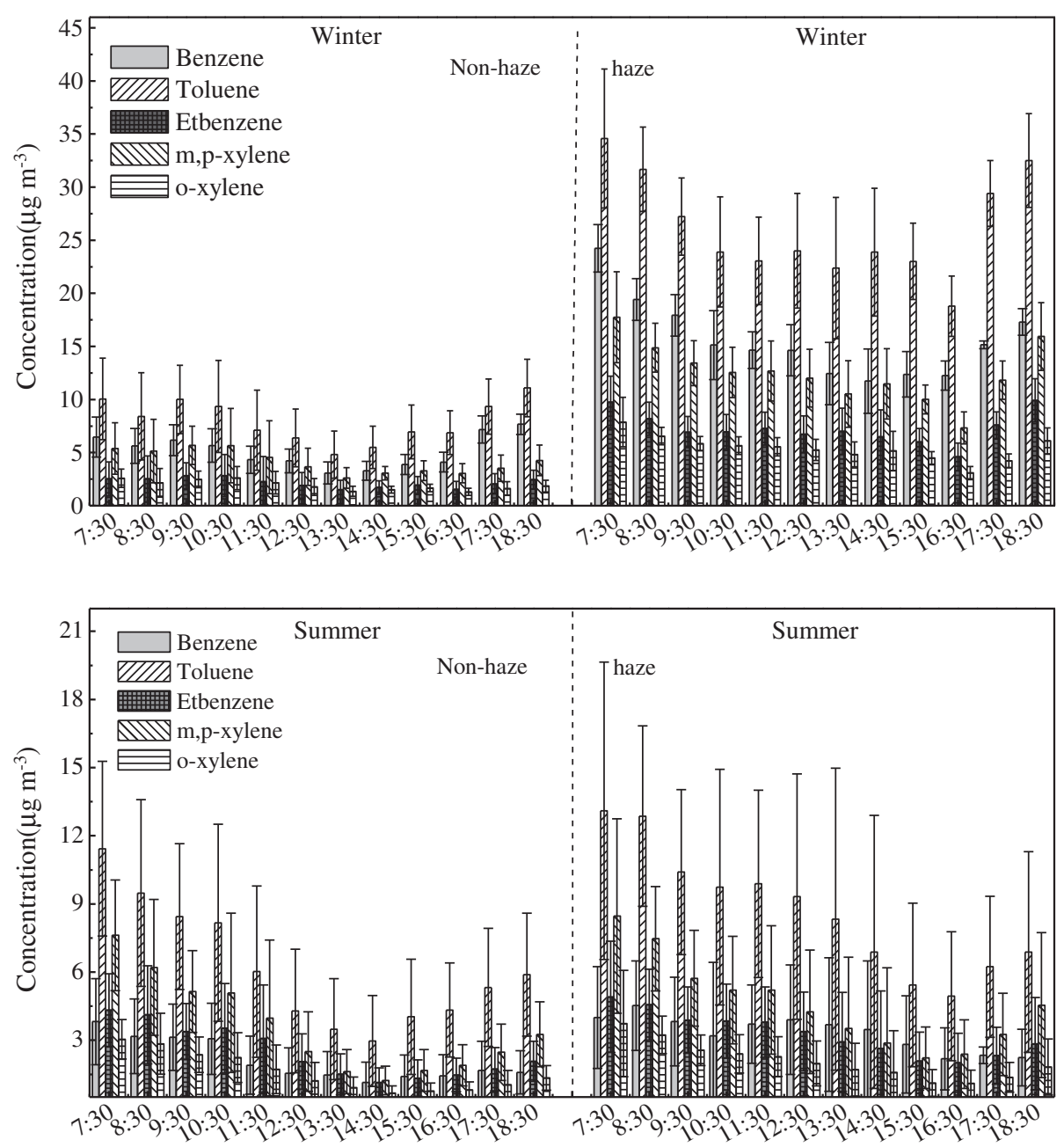

Fig. 1. Average diurnal variations of BTEX under haze days and non-haze days in winter and summer.

Table 1

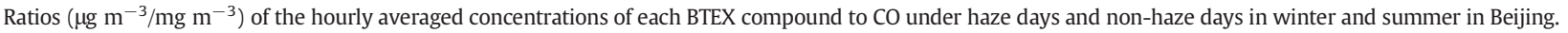

\begin{tabular}{|c|c|c|c|c|c|c|c|c|c|c|}
\hline \multirow[t]{2}{*}{ Time } & \multicolumn{2}{|c|}{ Benzene/CO } & \multicolumn{2}{|c|}{ Toluene/CO } & \multicolumn{2}{|c|}{ Ethylbenzene/CO } & \multicolumn{2}{|c|}{$m, p$-xylene/CO } & \multicolumn{2}{|c|}{ o-xylene/CO } \\
\hline & Non & Haze & Non & Haze & Non & Haze & Non & Haze & Non & Haze \\
\hline \multicolumn{11}{|c|}{ Ratios in winter } \\
\hline $7: 35$ & 2.06 & 6.00 & 3.20 & 8.35 & 0.80 & 2.51 & 1.72 & 4.05 & 0.82 & 1.80 \\
\hline $8: 34$ & 1.77 & 5.01 & 2.65 & 8.26 & 0.79 & 2.38 & 1.62 & 3.67 & 0.78 & 1.62 \\
\hline 9:30 & 2.10 & 4.56 & 3.41 & 6.94 & 0.96 & 1.95 & 1.94 & 3.30 & 0.85 & 1.44 \\
\hline $10: 30$ & 2.17 & 3.82 & 3.58 & 5.86 & 1.09 & 1.69 & 2.17 & 3.08 & 1.00 & 1.37 \\
\hline $11: 30$ & 1.75 & 3.58 & 2.87 & 5.54 & 0.91 & 1.74 & 1.84 & 3.05 & 0.87 & 1.34 \\
\hline $12: 30$ & 2.13 & 3.88 & 3.23 & 6.24 & 0.97 & 1.76 & 1.85 & 3.11 & 0.89 & 1.39 \\
\hline $13: 30$ & 1.76 & 3.17 & 2.75 & 5.70 & 0.86 & 1.78 & 1.50 & 2.68 & 0.77 & 1.23 \\
\hline $14: 30$ & 1.79 & 3.10 & 3.00 & 5.94 & 0.93 & 1.60 & 1.67 & 2.82 & 0.82 & 1.24 \\
\hline $15: 30$ & 2.27 & 3.26 & 4.07 & 5.72 & 1.14 & 1.47 & 1.93 & 2.47 & 0.98 & 1.10 \\
\hline $16: 30$ & 2.26 & 3.41 & 3.79 & 5.29 & 0.85 & 1.22 & 1.68 & 2.13 & 0.72 & 0.85 \\
\hline $17: 30$ & 3.61 & 3.95 & 4.71 & 6.86 & 1.04 & 1.73 & 1.78 & 2.71 & 0.82 & 1.03 \\
\hline $18: 30$ & 3.33 & 4.03 & 4.82 & 6.92 & 1.07 & 2.09 & 1.86 & 3.35 & 0.80 & 1.32 \\
\hline \multicolumn{11}{|c|}{ Ratios in summer } \\
\hline $7: 35$ & 1.13 & 1.11 & 3.63 & 3.45 & 1.44 & 1.29 & 2.59 & 2.20 & 1.01 & 1.00 \\
\hline $8: 34$ & 0.84 & 1.08 & 2.92 & 2.87 & 1.33 & 1.13 & 2.00 & 1.80 & 0.89 & 0.79 \\
\hline 9:30 & 0.99 & 1.02 & 3.03 & 2.64 & 1.23 & 1.04 & 1.89 & 1.48 & 0.87 & 0.65 \\
\hline $10: 30$ & 0.98 & 0.96 & 3.06 & 2.52 & 1.38 & 1.02 & 2.05 & 1.33 & 0.89 & 0.61 \\
\hline $11: 30$ & 0.70 & 0.92 & 2.48 & 2.43 & 1.31 & 0.94 & 1.73 & 1.26 & 0.72 & 0.55 \\
\hline $12: 30$ & 0.81 & 0.91 & 2.31 & 2.08 & 1.11 & 0.75 & 1.36 & 0.94 & 0.66 & 0.44 \\
\hline $13: 30$ & 0.85 & 1.00 & 2.09 & 2.26 & 0.90 & 0.79 & 0.96 & 0.95 & 0.55 & 0.45 \\
\hline $14: 30$ & 0.55 & 0.96 & 1.53 & 1.79 & 0.60 & 0.67 & 0.68 & 0.75 & 0.37 & 0.41 \\
\hline $15: 30$ & 0.83 & 0.75 & 2.45 & 1.42 & 0.81 & 0.53 & 1.02 & 0.57 & 0.46 & 0.28 \\
\hline $16: 30$ & 0.79 & 0.63 & 2.36 & 1.43 & 0.80 & 0.59 & 1.05 & 0.69 & 0.45 & 0.31 \\
\hline $17: 30$ & 0.84 & 0.62 & 2.68 & 1.82 & 0.87 & 0.68 & 1.25 & 0.96 & 0.53 & 0.40 \\
\hline $18: 30$ & 0.69 & 0.60 & 2.56 & 1.89 & 0.90 & 0.81 & 1.42 & 1.29 & 0.58 & 0.51 \\
\hline
\end{tabular}


compound to CO under both haze days and non-haze days exhibited their minimal values in the afternoon both in winter and summer, indicating evident consumption of atmospheric BTEX in the afternoon. It is interesting to note that the ratios of each BTEX to CO were extremely greater under haze days than those under non-haze days in winter, but no evident difference was found in summer. The sources for BTEX and $\mathrm{CO}$ in Beijing are dominated by automobile in summer, whereas governed by both automobile and fossil fuel used as energy for heating in winter (Zhang et al., 2012a, 2012b). The ratios of BTEX to CO under non-haze days may be strongly influenced by their regional background ratios because of the well diffusion condition with relatively high PBL, but the ratios were dominated by local emissions under the stagnant air condition of haze days. The extremely high ratios under haze days in winter indicated that the fossil fuel used as energy for heating in Beijing emitted the pollutants with high ratio of BTEX to CO. In addition, the photochemical reactivity under haze days in summer was much stronger than that in winter (indicated by the ratio of ethylbenzene $/ m$, $p$-xylene as discussed in the following section), and hence large fraction of accumulated BTEX under haze days in summer could be consumed by photochemical reactions and resulted in relatively low ratios of BTEX to CO.

\subsection{The photochemical reactivity under haze days}

To further elucidate the photochemical reactivity under haze days, the average diurnal variations of $\mathrm{E} / \mathrm{X}$ (ethylbenzene $/ m, p$-xylene) under different weather conditions (the haze days, the typical clear days and cloudy days) in summer and winter are illustrated in Fig. 2. The $\mathrm{E} / \mathrm{X}$ ratio is usually used as the indicator for photochemical reactivity, because $m, p$-xylene and ethylbenzene are usually from common sources in the urban atmosphere and the rate constant of $m, p$-xylene with $\mathrm{OH}$ radical is about 3 times faster than that of ethylbenzene (Atkinson, 1990; Nelson and Quigley, 1983). The evidently larger E/X ratios under haze days during both winter and summer than those under clear and cloudy days as well the distinct diurnal variations of the $\mathrm{E} / \mathrm{X}$ ratios well indicated high photochemical reactivity under haze days. Such high photochemical reactivity under haze days has also been found in our previous study during the 2008 Olympic Games (Liu et al., 2009a). The typical characters of haze days are abundant fine particles and relatively high humidity, which favor heterogeneous reaction of $\mathrm{NO}_{2}$ with $\mathrm{H}_{2} \mathrm{O}$ to form $\mathrm{HONO}$. Although sunlight intensity
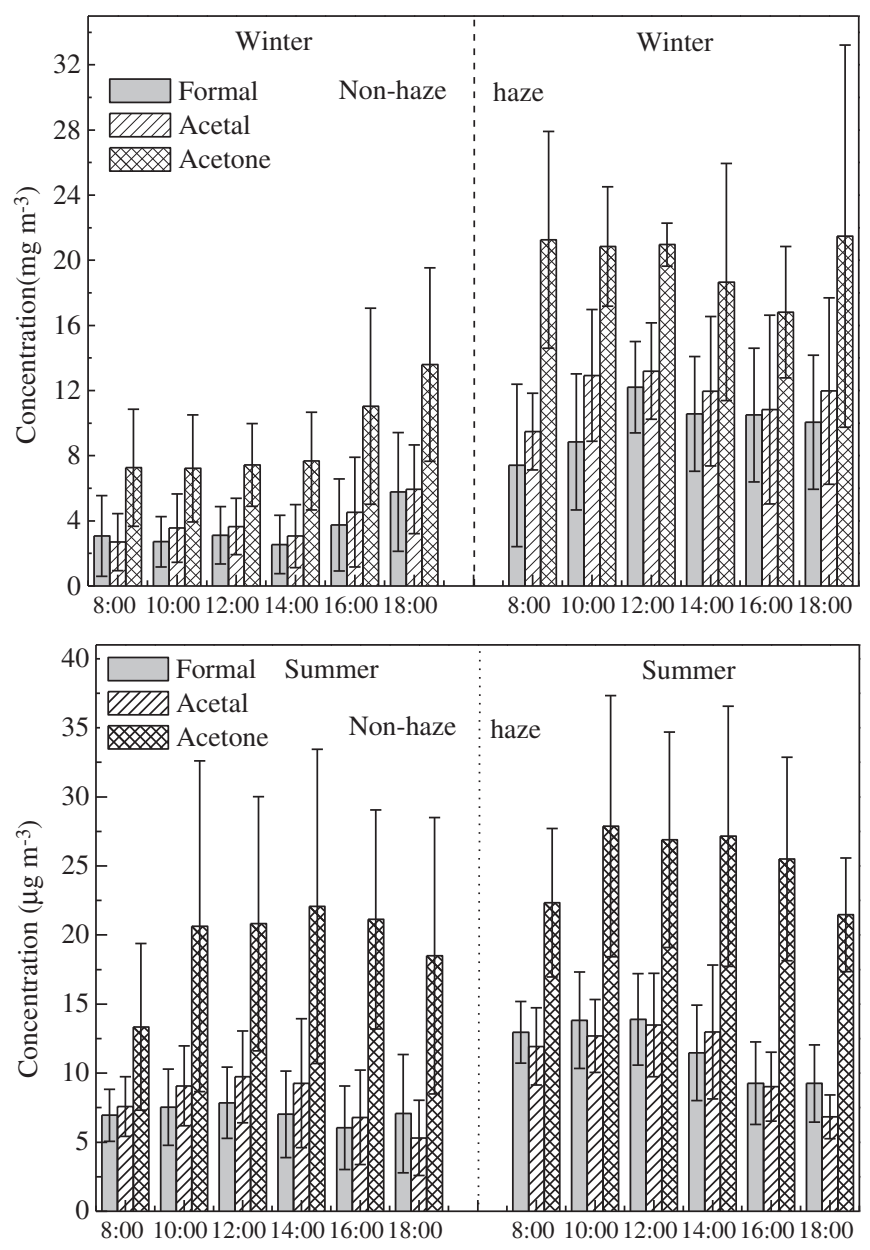

Fig. 3. Average diurnal variations of three principle carbonyls under haze days and nonhaze days in winter and summer.

under serious haze days is usually very low, the weak sunlight is enough for photolysis of HONO to produce OH radicals, which has been usually considered as the initiator for triggering photochemical reactions in the
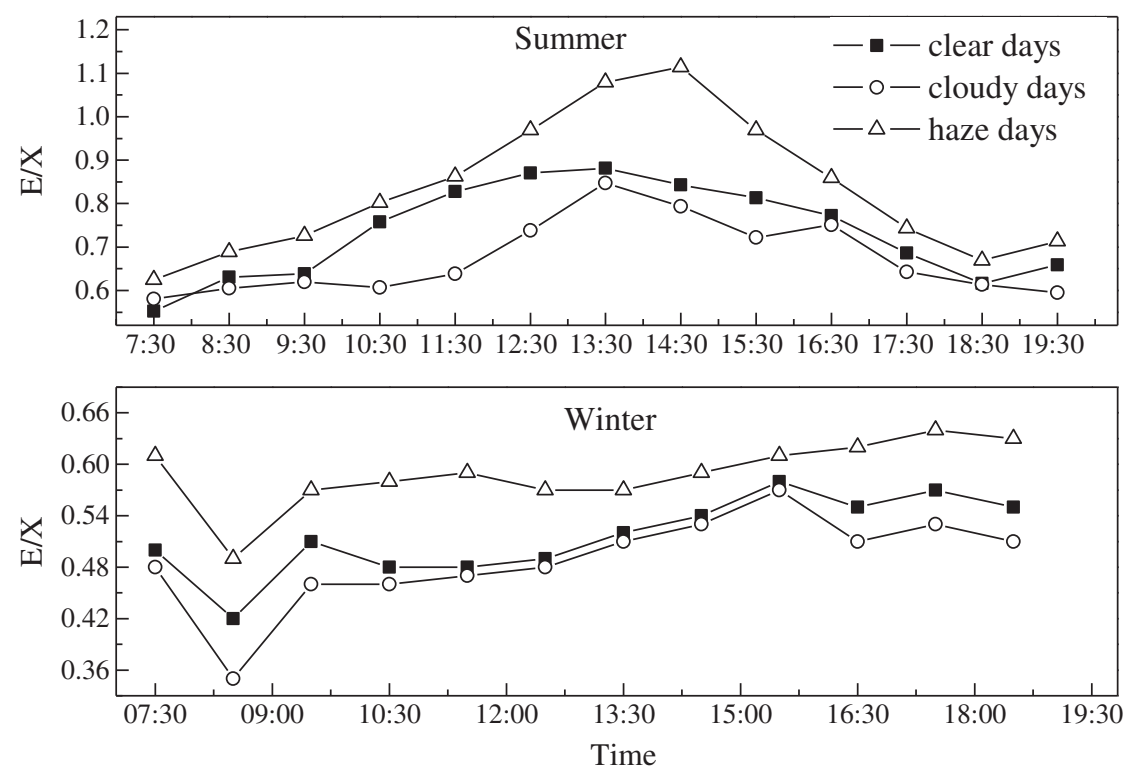

Fig. 2. The average diurnal variations of ethylbenzene/m,p-xylene $(\mathrm{E} / \mathrm{X})$ under three typical days in summer and winter. 
Table 2

Ratios ( $\mu \mathrm{g} \mathrm{m}^{-3} / \mathrm{mg} \mathrm{m}^{-3}$ ) of the 2-hourly averaged concentrations of the principle carbonyl compounds to $\mathrm{CO}$ under haze days and non-haze days in winter and summer in Beijing.

\begin{tabular}{|c|c|c|c|c|c|c|}
\hline \multirow[t]{2}{*}{ Time } & \multicolumn{2}{|c|}{ Formaldehyde } & \multicolumn{2}{|c|}{ Acetaldehyde } & \multicolumn{2}{|c|}{ Acetone } \\
\hline & Non & Haze & Non & Haze & Non & Haze \\
\hline \multicolumn{7}{|c|}{ Ratios in winter } \\
\hline $8: 00$ & 0.53 & 0.79 & 0.47 & 1.01 & 1.26 & 2.25 \\
\hline $10: 00$ & 0.58 & 0.83 & 0.75 & 1.22 & 1.53 & 1.96 \\
\hline $12: 00$ & 0.78 & 1.44 & 0.92 & 1.56 & 1.87 & 2.48 \\
\hline $14: 00$ & 0.63 & 1.30 & 0.76 & 1.47 & 1.91 & 2.29 \\
\hline $16: 00$ & 0.82 & 1.35 & 0.99 & 1.39 & 2.41 & 2.16 \\
\hline $18: 00$ & 0.91 & 1.11 & 0.94 & 1.33 & 2.14 & 2.38 \\
\hline \multicolumn{7}{|c|}{ Ratios in summer } \\
\hline $8: 00$ & 2.35 & 3.39 & 2.47 & 3.12 & 4.38 & 5.75 \\
\hline $10: 00$ & 2.93 & 3.38 & 3.48 & 3.16 & 8.07 & 6.81 \\
\hline $12: 00$ & 3.64 & 3.35 & 4.62 & 3.17 & 9.82 & 6.34 \\
\hline $14: 00$ & 4.06 & 2.91 & 5.24 & 3.28 & 12.46 & 6.62 \\
\hline $16: 00$ & 3.45 & 2.56 & 3.95 & 2.45 & 11.97 & 6.78 \\
\hline $18: 00$ & 3.35 & 2.52 & 2.62 & 1.90 & 8.24 & 5.92 \\
\hline
\end{tabular}

early morning. The maximum $\mathrm{E} / \mathrm{X}$ ratios under three type days in summer were about a factor of 2 greater than those in winter, revealing the stronger photochemical reactivity in summer.

\subsection{The influence of the haze on the atmospheric carbonyls}

Nine carbonyls were identified in Beijing ambient air during the sampling period. Among the identified carbonyls, formaldehyde, acetaldehyde and acetone were found to be the most abundant species and could be detected in every sample. Therefore, only the three carbonyls were analyzed for recognizing the possible influence of haze on their distribution.

Fig. 3 illustrates the average diurnal variations of the three principal carbonyl compounds under haze days and non-haze days in winter and summer. Like BTEX compounds, evident enhancement of atmospheric carbonyls was found under haze days in comparison with under nonhaze days both in winter and summer, with enhancement factors of 1.5-4.2 in winter and of 1.2-1.9 in summer. In contrast to BTEX, the concentrations of carbonyls under both haze and non-haze days were much higher in summer than in winter, confirming that the extremely high photochemical reactivity in summer makes great contribution to atmospheric carbonyls in Beijing (Pang and Mu, 2006; Dutta et al., 2009; Liu et al., 2009b; Xu et al., 2010; Zhang et al., 2012a, 2012b).

The 2-hour averaged ratios of each carbonyl compound to $\mathrm{CO}$ under haze days and non-haze days in winter and summer are listed in Table 2. In contrast to the ratios of BTEX compounds to $\mathrm{CO}$, the ratios of the three principal carbonyls to CO were usually found their maximal values in the afternoon under both haze and non-haze days in winter and summer, revealing the contribution of photochemical reactions to the carbonyls under the intensive sunlight irradiation in the afternoon. Like the atmospheric concentrations of the carbonyls, the ratios under both haze days and non-haze days in summer were at least a factor of 2 greater than those in winter, which provided further evidence that the extremely high photochemical reactivity in summer makes great contribution to atmospheric carbonyls in Beijing. As mentioned in Section 3.2, the photochemical reactivity was usually higher under haze days than non-haze days, and hence higher ratios of the carbonyls to $\mathrm{CO}$ under haze days than under non-haze days were expected. However, only slight enhancement of the ratios under haze days was found in winter, and even a decrease of the ratios under haze days was found in summer. Therefore, possible loss of the carbonyls on the surface of particles was suspected under haze days.

\section{Conclusions}

The influence of haze on atmospheric BTEX and carbonyls was discussed. Levels of the pollutants were found to be significantly increased under haze days in comparison with non-haze days due to the stagnant weather conditions of haze days. The much higher ratio of ethylbenzene to $m, p$-xylene under haze days both in summer and winter indicated the stronger photochemical reactivity. In comparison with winter, the extremely low ratios of BTEX to CO under haze days in summer were ascribed to the stronger photochemical reactivity under haze days in summer than those in winter. The evidently higher ratios of each carbonyl to $\mathrm{CO}$ in summer than those in winter suggested the great contribution of secondary formation to the carbonyls in summer.

\section{Acknowledgments}

This work was supported by the China Postdoctoral Science Foundation (2013M530687), the Chinese National Natural Science Foundation (21307121, 41075094, 21177140 and 20977097), the Special Fund for Environmental Research in the Public Interest (201009001), the Strategic Priority Research Program of the Chinese Academy of Sciences (XDB05010100), the National Basic Research and the Development Program 973 (2010CB732304) and the Strategic Pilot Science and Technology Project of Chinese Academy of Sciences (Class B) (No. XDB05010200).

\section{References}

Atkinson R. Gas-phase tropospheric chemistry of organic compounds: a review. Atmos Environ 1990;24A:1-41.

Atkinson R. Gas-phase tropospheric chemistry of volatile organic compounds 1. Alkanes and alkenes. J Phys Chem Ref Data 1997;26:215-90.

Atkinson R, Arey J. Gas-phase tropospheric chemistry of biogenic volatile organic compounds: a review. Atmos Environ 2003:37:197-219.

Baez AP, Padillah H, Garcia R, Torres M, Rosas I, Belmont R. Carbonyl levels in indoor and outdoor air in Mexico City and Xalapa, Mexico. Sci Total Environ 2003;302:211-26.

Barletta B, Meinardi S, Simpson IJ, Zou S, Rowland FS. Ambient mixing ratios of nonmethane hydrocarbons (NMHCs) in two major urban centers of the Pearl River Delta (PRD) region: Guangzhou and Dongguan. Atmos Environ 2008;42:4393-408.

Carlier P, Hannachi H, Mouvier G. The chemistry of carbonyl compounds in the atmosphere. Atmos Environ 1986;20:2079-99.

Committee on Toxicology, Environmental Health Hazards National Research Council. Formaldehyde and other aldehydes. Washington D C: National Academy Press; 1981.

Crump KS. Risk of benzene-induced leukemia: a sensitivity analysis of the pliofilm cohort with additional follow-up and new exposure estimates. J Toxicol Environ Health 1994;42:219-42.

Dutta C, Som D, Chatterjee A, Mukherjee AK, Jana TK, Sen S. Mixing ratios of carbonyls and BTEX in ambient air of Kolkata, India and their associated health risk. Environ Monit Assess 2009;148:97-107.

EPA. Compendium of methods for the determination of toxic organic compounds in ambient air2nd ed. ; 1999.

Haagen-Smit AJ, Fox MM. Ozone formation in photochemical oxidation of organic substance. Ind Eng Chem 1956;48:1484-7.

Hoque RR, Khillare PS, Agarwal T, Shridhar V, Balachandran S. Spatial and temporal variation of BTEX in the urban atmosphere of Delhi, India. Sci Total Environ 2008;392(1):30-40.

Liu J, Mu YJ, Zhang YJ, Zhang ZM, Wang X, Liu Y, et al. Atmospheric levels of BTEX compounds during the 2008 Olympic Games in the urban area of Beijing. Sci Total Environ 2009a:408:109-16

Liu Y, Shao M, Kuster WC, Goldan PD, Li X, Lu S, et al. Source identification of reactive hydrocarbons and oxygenated VOCs in the summertime in Beijing. Environ Sci Technol 2009b;43:75-81.

Lü HX, Cai QY, Wen S, Chi YG, Guo SJ, Sheng GY, et al. Carbonyl compounds in the ambient air of hazy days and clear days in Guangzhou, China. Atmos Res 2009;94(3):363-72.

Mao T, Wang YS, Jiang J, Wu FK, Wang XM. The vertical distributions of VOCs in the atmosphere of Beijing in autumn. Sci Total Environ 2008;390(1):97-108.

Nelson PF, Quigley SM. The m, p-xylenes: ethylbenzene ratio, a technique for estimating hydrocarbon age in ambient atmospheres. Atmos Environ 1983;17:659-62.

Pang X, Mu YJ. Seasonal and diurnal variations of carbonyl compounds in Beijing ambient air. Atmos Environ 2006:40:6313-20.

Pang X, Mu YJ. Characteristics of carbonyl compounds in public vehicles of Beijing city: concentrations, sources, and personal exposures. Atmos Environ 2007;41:1819-24.

Possanzini M, Palo VD, Cecinato A. Sources and photodecomposition of formaldehyde and acetaldehyde in Rome ambient air. Atmos Environ 2002;36:3195-201.

Quan JN, Gao Y, Zhang Q Tie XX, Cao JJ, Han SQ et al. Evolution of planetary boundary layer under different weather conditions, and its impact on aerosol concentrations. Particuology 2013;11:34-40. 
Satsumabayashi H, Kurita H, Chang YS, Carmichael GR, Ueda H. Photochemical formations of lower aldehydes and lower fatty acids under long-range transport in central Japan. Atmos Environ 1995;29:255-66.

Stupfel M. Recent advances in investigations of toxicity of automotive exhaust. Environ Health Perspect 1976;17:258-79.

Wang XM, Sheng GY, Fu JM, Chan CY, Lee SC, Chan LY, et al. Urban roadside aromatic hydrocarbons in three cities of the Pearl River Delta, People's Republic of China. Atmos Environ 2002;36:5141-8.
Xu Z, Liu J, Zhang Y, Liang P, Mu Y. Ambient levels of atmospheric carbonyls in Beijing during the 2008 Olympic Games. [China] J Environ Sci 2010;22(9):1348-56.

Zhang Y, Mu Y, Liu J, Mellouki Abdelwahid. Levels, sources and health risks of carbonyls and BTEX in the ambient air of Beijing, China. J Environ Sci 2012a;22(9):1348-56.

Zhang Y, Mu Y, Liang P, Xu Z, Liu J, Zhang H, et al. Atmospheric BTEX and carbonyls in summer seasons of 2008-2010 in Beijing. Atmos Environ 2012b;59:186-91. 